\title{
The employment of spectroscopic techniques coupled with chemometrics for authentication analysis of halal pharmaceuticals
}

\author{
Abdul Rohman ${ }^{1,2^{*}}$, Nina Salamah ${ }^{1}$ \\ ${ }^{1}$ Faculty of Pharmacy, Universitas Gadjah Mada, Yogyakarta, 55281, Indonesia. \\ ${ }^{2}$ Research Center of Halal Products, Universitas Gadjah Mada, Yogyakarta, 55281, Indonesia.
}

\section{ARTICLE INFO \\ Article history: \\ Received on: 01/05/2018 \\ Accepted on: 15/08/2018 \\ Available online: 31/10/2018}

\section{Key words:}

molecular spectroscopy,

pig derivatives, halal

pharmaceutical,

chemometrics.

\begin{abstract}
Halal authentication analysis is very important to assure that the pharmaceutical products are free from non-halal components. Among non-halal matters, pig derivatives are frequently met in the market because pig derivatives (PDs) are cheaper and easily available. Molecular spectroscopy is an ideal technique for analysis of PDs in pharmaceutical products, due to its advantages, namely rapid, non-destructive, ease in operation and minimum or no sample preparation required. However, molecular spectra are sometimes overlapping and very complex which make molecular spectroscopy lack of sensitivity. Fortunately, the development of chemometrics techniques overcome this problem. This article reviewed the development of molecular spectroscopy (ultraviolet-visible, infrared, Raman, and nuclear magnetic resonance) in combination with chemometrics techniques for spectral treatment, classification, and quantification for analysis of PDs which include lard, pork and porcine gelatine for halal authentication analysis in pharmaceutical products.
\end{abstract}

\section{INTRODUCTION}

Halal is Arabic terms meaning allowed, permitted and wholesome. Regarding this terms, halal food is defined as any food or drink permissible to be consumed by Muslim according to shariah (Islamic) law, as revealed in the Quran or hadith (the tradition of Prophet Muhammad) (Khattak et al., 2011; Lubis et al., 2016). Muslim societies are not allowed to consume any products containing non-halal components, except under extremely exceptional condition. Non-halal components include carrion or dead animals, blood (flowing or congealed), pig derivatives (PDs) such as pork, lard and porcine gelatin, animals that are slaughtered with non-compliance to shariah law, animals that were killed accidentally or on purpose through means such as strangling or beating, all types of intoxicants such as alcohol and drugs, carnivorous animals with fangs such as lions, dogs, wolves, or tigers, predator birds such as falcons, eagles, owls, or vultures, and certain land animals such as snakes (Regenstein et al., 2003;

\footnotetext{
"Corresponding Author

Abdul Rohman, Faculty of Pharmacy, Universitas Gadjah Mada, Yogyakarta,55281, Indonesia.E-mail: abdul_kimfar@ugm.ac.id
}

Rohman and Che Man, 2012).

Due to the advancement of science and technology, the adulteration practices of pharmaceuticals either intentionally or not intentionally, have become a common issue in the pharmaceutical industry to gain economical benefits. PDs are usually cheaper than those of sheep and cattle. For example, the price of porcine gelatin used in capsule shells is cheaper than that of bovine gelatin, as a consequence PDs are used as an adulterant in pharmaceutical products. Non-authentic pharmaceuticals can be defined as pharmaceuticals which are not fitted as in claimed labeled. Intentionally, halal inauthenticity can take in the forms of partial or total substitution of halal components with non-halal ones such the substitution of bovine gelatin with porcine gelatin in capsule shells (Nakyinsige et al., 2012). Halal inauthenticity can also occur through the contamination of trace amount of non-halal components unintentionally. Among those non-halal components, PDs are chosen as adulterants in halal pharmaceuticals because they are cheap and readily available. PDs refer to any components derived from a pig (Sus scrofa) such as lard obtained from pig fat, pork (pig meat), and any gelatines produced from the bone and skin of a pig (Rohman and Che Man, 2012). 
Several analytical approaches have been used for analysis of PDs in pharmaceutical products which depend on the levels and matrix of evaluated samples. The first approach is to determine the specific ratios of certain components in adulterated pharmaceuticals so that any addition of PDs will change these ratios. Secondly, chemists can search a specific marker in pharmaceuticals products, either chemical or biological proving the presence of PDs in pharmaceuticals products, and thirdly is the use of an analytical instrument such as spectrophotometer for detection of PDs in pharmaceuticals products (Cordella et al., 2002).

\section{Molecular spectroscopy}

Molecular spectroscopy is a field of study related to the interaction between electromagnetic radiation (EMR) in certain regions with samples in the molecular levels (to differentiate with atomic spectroscopy) (Davidson, 2002). Ultraviolet-visible (uvvis spectroscopy) is taken into account as the interaction between EMR in regions of $200-800 \mathrm{~nm}$ with evaluated samples, while infrared (IR) spectroscopy takes place in regions of 800-25000 nm (Skoog et al., 2007; Pavia et al., 2009). Over the past two decades, there is an increasing interest among communities of research and industry in the use of molecular spectroscopy methods which include uv-vis and fluorescence, vibrational spectroscopy (infrared and Raman) and nuclear magnetic resonance (NMR). Molecular spectroscopies offer some advantages, namely non-destructive, minimum or no sample preparation required, ease in operation and the speed of the analysis (Cozzolino, 2015).

Ultraviolet-visible (uv-vis) spectroscopy can be used for qualitative and quantitative analyses based on the interaction of a photon in the region of 200-400 nm (ultraviolet) and 400800 (visible) with samples. This interaction resulted in electronic transition of samples, in which electrons are excited from the ground state into an excited state. In order to quantify the analyte(s) of interest (non-halal components), the absorbance based on Lambert-Beer law was used instead of transmittance. The samples must have chromophores to be analyzed with this method. Due to lack of chromophores and auxochromes, this spectroscopic method is not widely used for analysis of PDs (Behera et al., 2012).

Various fluorescence spectroscopic techniques (conventional, synchronous fluorescence, and excitation-emission matrix spectroscopy) are fast, sensitive, non-destructive, and able to analyze PDs in any matrix samples (Sádecká and Tóthová, 2007). The fluorescence spectra are characteristically composed of wide overlapping fluorescence spectral bands which contain information on chemical, physical, and structural of all evaluated samples. The information of an analytical signal contained in fluorescence spectra is rather complex in nature and, therefore, this technique is non-selective. Besides, the differences among evaluated samples may cause slight spectral differences that are difficult to distinguish. As a consequence, fluorescence spectra can be threated using various chemometrics techniques that relate several analytical variables to the properties of the analyte(s) (Norgaard, 1995).

Infrared (IR) spectroscopy, either in near or mid regions, has emerged as potential tools for analysis of PDs. IR spectroscopy is fast, easy to use, require minimum samples, not involving extensive sample preparation, and non-destructive which means that samples measured using IR spectroscopy can be analyzed using other instruments, and fingerprint in nature. However, the obtained signals are rather complex which make it difficult to interpret, therefore, the use of chemometrics to solve the problems related to IR spectral interpretation and analysis is unavoidable (Rohman, 2012; Wang et al., 2016). IR spectroscopy is based on the interaction between samples with EMR in IR region resulted in vibrational transition of chemical bonds, therefore, IR and Raman spectroscopy are called as vibrational spectroscopy. Two units are frequently used in IR spectroscopy, namely wavelength $(\mathrm{nm})$ and wavenumbers $\left(\mathrm{cm}^{-1}\right)$. IR regions are divided into three regions of near $\left(0.8-2.6 \mu \mathrm{m}\right.$ or $\left.14,000-400 \mathrm{~cm}^{-1}\right)$, mid $(2.6-26$ $\mu \mathrm{m}$ or $\left.4000-400 \mathrm{~cm}^{-1}\right)$ and far $\left(26-100 \mu \mathrm{m}\right.$ or $\left.400-10 \mathrm{~cm}^{-1}\right)$. The unit of wavelength $(\mu \mathrm{m})$ is used during analysis with near IR and wavenumbers unit $\left(\mathrm{cm}^{-1}\right)$ is commonly used for analysis with mid IR (Gendrin et al., 2008; Rohman, 2017).

Near-infrared (NIR) spectra are the consequence of the absorbance or transmission of light due to the molecular vibrations of functional groups due to the overtones and combinations of fundamental vibrations (Fermi resonance). The most prominent groups responsible for NIR absorption are hydrogen bonds like C-H, N-H, O-H and S-H (Luypaert et al., 2007). The spectral bands of NIR absorption are typically overlapping, broad, and 10-100 times weaker than those of corresponding fundamental mid-IR absorption spectral bands, make NIR spectra difficult to interpret. The main drawback of NIR spectroscopy is its high detection limit, which is not suitable for quantitative analysis of trace analysis (Reich, 2005).

IR spectroscopy in mid IR region is the commonly used for qualitative and quantitative analysis of PDs due to the large information obtained. The IR spectrum revealed wavenumbers in $\mathrm{x}$-axis and intensity (transmittance or absorbance) in the $y$-axis, coming from vibrational and rotational transitions of chemical bonds among atoms within the molecule (Hannah, 2002). IR spectra are traditionally used for qualitative analysis (identification) by identifying specific functional groups present in molecules. In recent years, with the development of multivariate calibration, IR spectroscopy is widely exploited for quantitative analysis. For qualitative analysis, either absorbance or transmittance can be used. Meanwhile, the absorbance mode must be used in quantitative analysis according to Lambert-Beer law (Griffiths and Chalmers, 1999).

Raman spectroscopy and IR spectroscopy are complementary spectroscopic methods. Raman spectrum is obtained by focusing monochromatic radiation on a sample and analyzing the scattered light as a function of frequency. This irradiation resulted in two types of light scattering, namely elastic and inelastic. Raman spectroscopy relies upon inelastic scattering of EMR by a molecular system (Wartewig and Neubert, 2005). The elastic scattering occurring at the same wavelength as that of irradiated light is known as Rayleigh scattering. Due to gain or loss of energy, this inelastic scattering is accompanied by photon frequency shift and its wavelength is changed which results in Raman scattering. In Raman scattering, molecule subjected with an incident photon is excited from the ground state to the excited state, which immediately relaxed to ground electronic or vibrational states and undergo a wavelength shift (Kalantri et 
al., 2010). Numerous types of Raman spectroscopic techniques namely transmission, Raman spectroscopy, Fourier transformRaman spectroscopy, and surface-enhanced Raman scattering have been introduced and have been developed for analysis of PDs (Chen et al., 2017). Raman spectra are presented as an intensity (y-axis) versus wavelength shift recorded over a range of 4000-10 $\mathrm{cm}^{-1}$ (y-axis). The spectrum of Raman is simpler than that of its IR counterpart in term of bands, as Raman's overtones, combinations, and differences are rare. Like IR spectrophotometer, Raman spectrophotometers can be either dispersive or nondispersive using Fourier transformation (FT-Raman spectrophotometer) (Bumbrah and Sharma, 2016). Infrared and Raman spectroscopies are considered as vibrational spectroscopy due to its vibration phenomenon when samples were subjected to infrared radiation. Rohman et al. (2016) have reviewed the use of this vibrational spectroscopic technique for analysis of PDs, especially in food matrix samples (Rohman et al., 2016) and also for the authentication of herbal medicines (Rohman et al., 2014).

Nuclear Magnetic Resonance (NMR) spectroscopy, based on absorption of EMR by specific isotopes of atomic nuclei, has been extensively used for the authentication analysis of food products and has been emerged as potential means for analysis of PDs for halal assessment (Dais and Hatzakis, 2013). Proton $\left({ }^{1} \mathrm{H}\right)$ NMR spectroscopy is more preferred over ${ }^{13} \mathrm{C}$-NMR due to its sensitivity and shorter relaxation time and faster analysis. NMR spectroscopy is taken into account as one of the most suitable methods to obtain "high throughput" spectroscopic methods containing information on the molecular chemical structure on large compounds. This method is capable of determining complex matrices with minimum sample preparation. Besides, NMR spectroscopy can analyze a large amount of metabolites including those present in PDs. Therefore, NMR spectroscopy especially in combination with chemometrics is an ideal method for metabolomics analysis (Danezis et al., 2016).

\section{Chemometrics}

One of the factors contributing to the success of molecular spectroscopy is the development of chemometrics software used for data treatment, especially for complex and overlapping spectra. Molecular spectra lack sensitivity, therefore, sometimes analytical chemists applied chemometrics techniques as an effective means to solve these problems (Bro et al., 1997; Bosque-Sendra et al., 2012). Chemometrics is a discipline of science which involve the employment of statistical and mathematical methods for extracting the useful information obtained during chemical measurement (spectra resulted from the molecular spectroscopic signal). According to International Chemometrics Society (ICS), chemometrics is defined as the science of relating chemical measurements made on a chemical system to the property of interest (such as concentration) through the application of mathematical or statistical methods (Gemperline, 2006).

For halal authentication analysis, chemometrics used for the treatment of spectra data is basically intended to two main purposes, namely qualitative purpose by making pattern recognition (classification and discrimination) and quantitative purpose by applying multivariate calibration model (Miller and Miller, 2010). Some spectra are also subjected to some processing before being used for making qualitative and quantitative analyses which include Savitzy-Golay-based derivatization, standard normal variate, mean centering, baseline corrections, signal correction and compression, spectra normalizations, and multiplicative corrections. Pattern recognition can be either unsupervised such as discriminant analysis and canonical correlation analysis (CCA) or supervised methods such as principal component analysis (PCA) and cluster analysis. In addition, multivariate calibration for the quantitative purpose includes stepwise multiple linear regression, multivariate curve resolution algorithms, genetic multivariate calibration, principal component regression and partial least square (Gad et al., 2013).

Some practical steps met in chemometrics analysis include experimental design, preprocessing of data, classification, and calibration. Design of experiment (DoE) is intended to make screening of important factors for the success of the analytical process. DoE is typically followed by the selection and application of optimum conditions under which the process will be performed, hence DoE is saving time (Hanrahan and Gomez, 2010). After the process has been optimized, the classification or calibration is carried out. Pre-processing of molecular spectra in the correct manner is very important. If the pre-processing is not performed, there will be a mix up between the signal of interest and noise which one not interested (Rinnan, 2014). In qualitative purpose, pre-processing is aimed to make optimum classification and discrimination among evaluated samples, while in quantitative analysis, pre-processing is intended to obtain pre-processed spectra which are directly correlated to concentration.

Halal authentication analysis frequently involved the quantification of PDs assisted by chemometrics of multivariate calibration. Three steps are carried out during quantitative analysis with molecular spectra, namely (1) optimization of wavelength capable of providing the optimum models in calibration and validation, (2) developing calibration model taking into account some statistical parameters including coefficient of determination $\left(\mathrm{R}^{2}\right)$ and root mean square error of calibration (RMSEC), (3) making validation using independent samples to evaluate the developed calibration model based on statistical parameters of $\mathrm{R}^{2}$, root mean square error of prediction (RMSEP), and predicted residual error sum of squares (PRESS) (Ragno et al., 2004; Hemmateenejad, 2006). Cross-validation using calibration samples employing "leave one out technique" was also common for validation of calibration models.

The chemometrics analysis is difficult to perform manually, fortunately, there is a number of user-friendly chemometrics software available to carry out calculations of complex data. Each program has its own features and advantages. The statistical software of Unscrambler ${ }^{\circledR}$, SIMCA ${ }^{\circledR}$, SIRIUS ${ }^{\circledR}$, and Pirouette ${ }^{\circledR}$ offer standard methods of multivariate analysis such as PCA, cluster analysis, PCR, PLS and Soft Independent Modelling of Class Analogy (SIMCA), but there is a little capacity to write personal programs. Conversely, Minitab $\AA$ and Matlab $\mathbb{R}$ are designed to facilitate the writing of personal routines, and Grams ${ }^{\circledR} 32$ is particularly useful for routine quantitative analysis rather than for exploration of data matrix by different pattern recognition techniques (Kokot et al., 1998). Currently, some instruments such as FTIR spectrophotometers and chromatographs are equipped with chemometrics software included as one package. 


\section{Analysis of lard using molecular spectroscopy}

Infrared spectroscopy and nuclear magnetic resonance are methods widely reported for analysis of lard as adulterants either in the mixture with other edible fats and oils or in the pharmaceutical products. Among molecular spectroscopies, infrared (IR) spectroscopy in near and mid regions is the most reported ones for analysis of lard as adulterants in other edible fats and oils or lard intentionally added to pharmaceutical products. Basri et al. (2017) have developed NIR spectroscopy at wavelength 950-1650 $\mathrm{nm}$ using transflectance and transmission sampling techniques for classification and quantification of lard as an adulterant in palm oil. The selection of variables (absorbance values at several wavelengths) was carried out using cumulative adaptive reweighted sampling (CARS), while classification and quantification were facilitated by soft independent modeling class analogy (SIMCA) and partial least square (PLS) calibration. The results showed that SIMCA can classify palm oil and palm oil adulterated with lard with a model accuracy of 0.93 (transflectance) and 0.95 (transmission). For quantitative analysis of lard, NIR spectroscopy combined with PLS can predict lard content described by an equation relating between the actual value of lard (x) and NIR-PLS predicted value (y) as:

$$
\begin{aligned}
& Y=0.9987 x+0.02032 \text { (transflectance) } \\
& Y=0.9994 x+0.01024 \text { (transmission) }
\end{aligned}
$$

NIR spectroscopy using transmission mode was better than that using transflectance mode for classification and quantification of lard in palm oil. Furthermore, Rohman et al. (2012) have analyzed lard adulteration in palm oil quantitatively using mid-infrared (MIR) spectroscopy combined with PLS regression. The absorbances (variables) at wavenumbers of 1480$1085 \mathrm{~cm}^{-1}$ offered a good relationship between the actual value of lard (x-axis) and FTIR predicted value (y-axis) with an equation of $y=0.9999 x-0.0366$, with $R^{2}$ of 0.998 . The root mean square error of calibration (RMSEC) and root mean square error of crossvalidation (RMSECV) were 1.69 and $2.87 \%$ respectively. These results could be extended for analysis of lard mixed with palm oil in any pharmaceutical products.

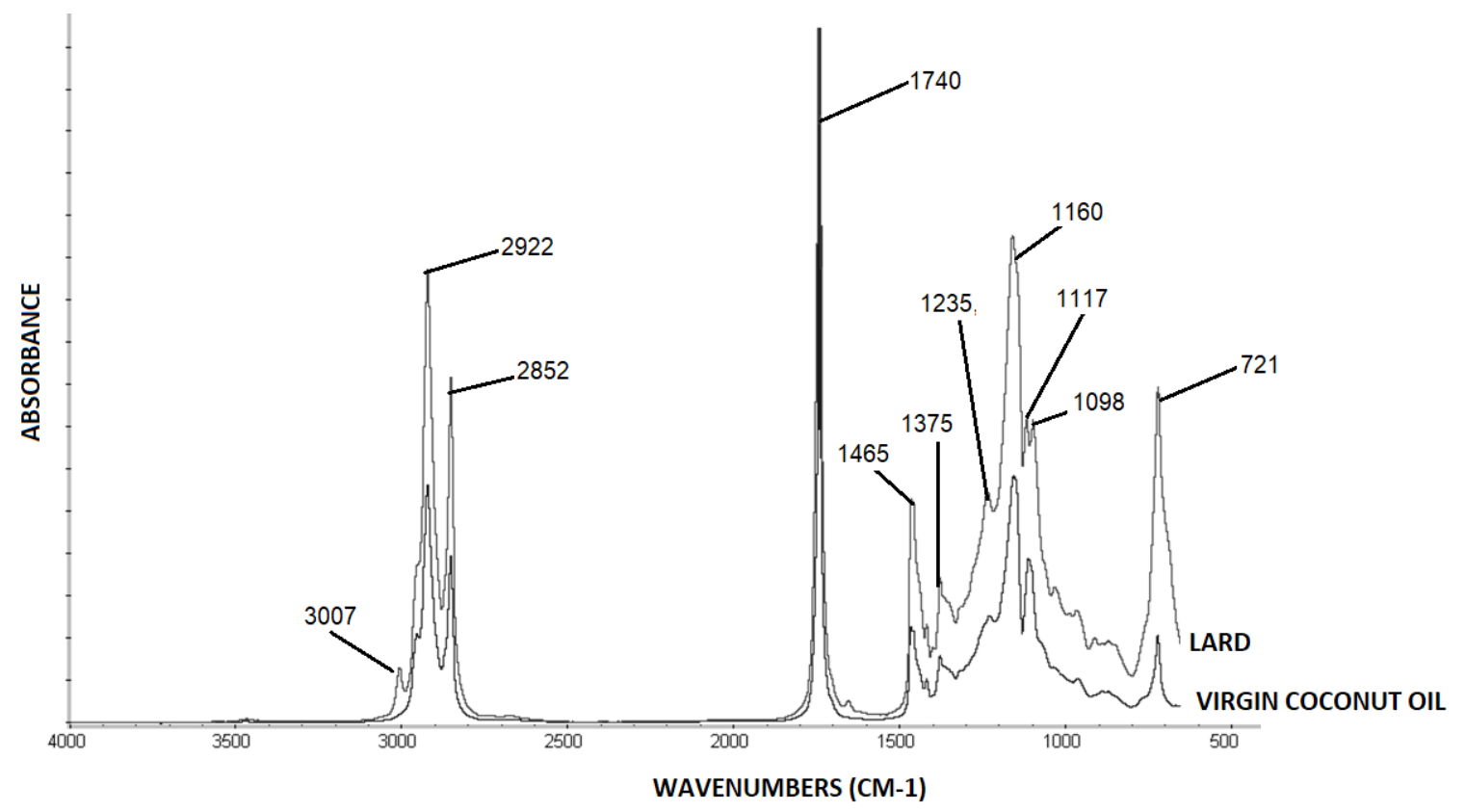

Fig. 1: FTIR spectra of lard and VCO at mid infrared region (4000-650 $\left.\mathrm{cm}^{-1}\right)$, taken from Rohman and Che Man (2011).

In the pharmaceutical field, lard may be used as components of drug vehicles or cosmetics components. Lard is considered as "generally recognized as safe substances (GRAS)" in pharmaceutical products. FTIR spectroscopy in combination with multivariate analysis have been developed for analysis of lard in the cream formulation (Rohman and Che Man, 2011), lard in lotion (Lukitaningsih et al., 2012) and lard in lipstick formulation (Waskito et al., 2016). The analytical steps include preparation of cosmetics preparation using lard as one of the components, extraction of lard from cosmetics samples using extraction methods such as Soxhlet, Bligh, and Dyer or Folch methods, FTIR spectra acquisition, development calibration and validation models, evaluation of models, and finally an analysis of lard in samples.

Rohman and Che Man (2011) have used FTIR spectroscopy combined with PLS and discriminant analysis for quantitative and discrimination of lard in the mixture with virgin coconut oil (VCO) in cream cosmetics. Figure 1 revealed FTIR spectra of lard and VCO at mid-infrared region (4000-650 $\mathrm{cm}^{-1}$ ). Each peak in Figure corresponding to functional groups responsible for IR absorption, as compiled in Table 1. PLS and DA used absorbances at the combined wavenumbers region of 3,0202,995 and 1,200-1,000 $\mathrm{cm}^{-1}$. PLS regression model obtained for the relationship between the actual value of lard (x) and FT-IR predicted value $(\mathrm{y})$ was:

$$
\mathrm{y}=0.997 \mathrm{x}+0.065\left(\mathrm{R}^{2} \text { of } 0.997 \text {; RMSEC of } 0.808 \%\right. \text {; }
$$

RMSECV of $1.93 \%$ )

Discriminant analysis (DA) based on Mahalanobis distance was successfully applied for discrimination between 
cream cosmetics with and without lard in its formulation (Figure 2). Lukitaningsih et al. (2012) used PLS and PCA for quantification and classification of lard in lotion cosmetics. Lard in lotion samples was extracted by hydrolysis of emulsifier using concentrated $\mathrm{HCl}$, separation of lipid fraction using chloroform, and removing chloroform to get lipid fraction. The lipid extracts obtained were further determined using FTIR spectrophotometer. The optimized wavenumbers of 1,200-1000 $\mathrm{cm}^{-1}$ were selected and successfully applied for quantification of lard using PLS and classification using PCA with acceptable statistical parameters.

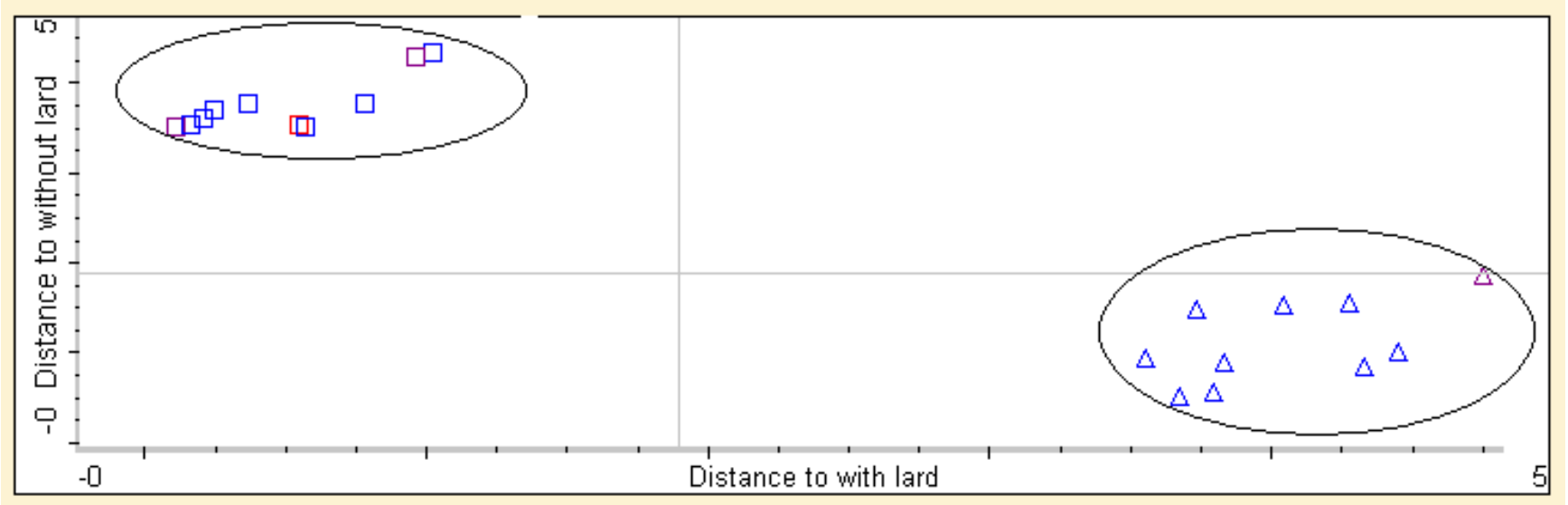

Fig. 2: The Coomans plot of cream cosmetics containing lard and that without lard in its formulations. $(\Delta)$ : The Mahalanobis distance to cream samples "with lard" in its formulation; (口) Mahalanobis distance to cream samples "without lard" using 9 PCs (taken from Rohman and Che Man, 2011).

Table 1: Functional groups responsible for IR absorption in lard and virgin coconut oil (Rohman and Che Man, 2011).

\begin{tabular}{|c|c|}
\hline $\begin{array}{l}\text { Wavenumbers } \\
\quad\left(\mathrm{cm}^{-1}\right)\end{array}$ & Functional groups and mode the vibration \\
\hline 3007 & C-H vinylic (stretching) \\
\hline 2922 & Methylene $\left(-\mathrm{CH}_{2}-\right)$ group (stretching) \\
\hline 2852 & Methyl $\left(-\mathrm{CH}_{3}\right)$ group (stretching) \\
\hline 1740 & $\begin{array}{l}\text { Carbonyl ester }(\mathrm{C}=\mathrm{O}) \text { of the triacylglycerol ester linkage with } \\
\text { strong intensity due to the great difference in electronegativity } \\
\text { properties between carbon and hydrogen atoms (stretching) }\end{array}$ \\
\hline 1465 & Methylene $\left(-\mathrm{CH}_{2}-\right)$ group (bending) \\
\hline 1375 & Methyl $\left(-\mathrm{CH}_{3}\right)$ group (bending) \\
\hline $\begin{array}{l}1235,1160,1117 \\
1098 \text { and } 721\end{array}$ & $\begin{array}{l}\text { The overlapping of the methylene (rocking vibrations) and } \\
\text { cis-disubstituted olefins (out of plane bending vibration) }\end{array}$ \\
\hline
\end{tabular}

For quantification and classification of lard in "rambak" crackers, Erwanto et al. (2016) have developed FTIR spectroscopy in combination with PLS and PCA at wavenumbers of 1200-1000 $\mathrm{cm}^{-1}$. The relationship between the actual value of lard and FTIR predicted value has $\mathrm{R}^{2}$ value in the calibration model of 0.946 with RMSEC of $2.77 \%$. PCA can be successfully used for determination of PDs through analysis of lard in commercial "rambak" crackers.

\section{Analysis of porcine gelatin}

FTIR spectroscopy using attenuated total reflectance (ATR) as sampling handling technique in combination with chemometrics of hierarchical cluster analysis and PCA has been developed for classification of gelatin sources (bovine, porcine, and fish) for halal authentication. The absorbances at regions of Amide-I (1700-1600 $\left.\mathrm{cm}^{-1}\right)$ and Amide-II (1565-1520 $\left.\mathrm{cm}^{-1}\right)$ were used as variables during HCA and PCA. FTIR spectral data at these regions coupled with PCA and HCA successfully discriminated against pure bovine gelatin from the mixture of bovine and porcine gelatins (Cebi et al., 2016). FTIR spectroscopy-ATR combined with PCA using absorbancies at $3290-3280 \mathrm{~cm}^{-1}$ and $1660-1200$ $\mathrm{cm}^{-1}$ can be successfully used for classification of bovine and porcine gelatines as indicated in Cooman's plot (Hashin et al., 2010).

\section{CONCLUSION}

Halal authentication analysis is very important not only for consumers but also for producers and regulatory agencies. One of the issues regarding halal authentication is the substitution and contamination of non-halal components in pharmaceutical and cosmetics products. Among non-halal components, pig derivatives (PDs) are frequently met in the pharmaceutical products which need the development of analytical methods for detection of PDs. Molecular spectroscopic techniques are a rapid and reliable method for screening of PDs, and in the future, these techniques must be standardized to be standard official methods for halal pharmaceuticals authentication.

\section{ACKNOWLEDGMENT}

The authors acknowledge to the Ministry of research and higher education via research grant project of Penelitian Unggulan Perguruan Tinggi (PUPT) awarded to Abdul Rohman, Ph.D.

\section{REFERENCES}

Basri KN, Hussain MN, Bakar J, Khir MFA, Zoolfakar AS, Sharif Z. Classification and quantification of palm oil adulteration via portable NIR spectroscopy. Spectrochim. Acta Part A, 2017; 173:335-342.

Behera S, Ghanty S, Ahmad F, Santra S, Banerjee S. UV-Visible Spectrophotometric Method Development and Validation of Assay of Paracetamol Tablet Formulation. J Anal Bioanal Techniques, 2012; 3:151. doi: 10.4172/2155-9872.1000151.

Bosque-Sendra JM, Cuadros-Rodríguez L, Ruiz-Samblás C, Paulina de la Mata A. Combining chromatography and chemometrics for the characterization and authentication of fats and oils from triacylglycerol compositional data-a review. Anal Chim Acta, 2012; 724:1-11.

Bro R, Jerome JW, Paul RM, Kowalski BR. Review of chemometrics applied to spectroscopy: 1985-95, Part 3-Multi-way analysis. App Spectros Rev, 1997; 32:37-261. 
Bumbrah GS, Sharma RM. Raman spectroscopy - Basic principle, instrumentation and selected applications for the characterization of drugs of abuse. Egyptian J Foren Sci, 2016; 6:209-215.

Cebi N, Durak MZ, Toker OS, Sagdic O, Arici M. An evaluation of Fourier transforms infrared spectroscopy method for the classification and discrimination of bovine, porcine and fish gelatins. Food Chem, 2016; 190:1109-1115.

Chen D-D, Xie X-F, Ao H, Liu J-L, Peng C. Raman spectroscopy in quality control of Chinese herbal medicine. J Chin Med Assoc, 2017; 80:288-296.

Cordella C, Moussa I, Martel AC, Sbirrazzuoli N, Cuvelier LL. Recent developments in food characterization and adulteration detection: Technique-oriented perspectives. J Agric Food Chem, 2002; 50:1751-1764.

Cozzolino D. The Role of Visible and Infrared Spectroscopy Combined with Chemometrics to Measure Phenolic Compounds in Grape and Wine Samples. Molecules, 2015; 20:726-737.

Dais P, Hatzakis E. Quality assessment and authentication of virgin olive oil by NMR spectroscopy: a critical review. Anal Chin Acta, 2013; 765:1-27.

Danezis GP, Tsagkaris AS, Camin F, Brusic V, Georgiou CA. Food authentication: Techniques, trends \& emerging approaches. Trends Anal Chem, 2016; 85:123-132.

Davidson AG. 2002. Ultraviolet-visible absorption spectrophotometry. In: Beckett AH, Stenlake JB, (4th Ed.), Practical Pharmaceutical chemistry. New Delhi: CBS Publishers and distributors 275-278.

Erwanto Y, Muttaqien AT, Sugiyono, Sismindari, Rohman A. Use of Fourier transform infrared (FTIR) spectroscopy and chemometrics for analysis of lard adulteration in "rambak" crackers. Int J Food Prop, 2016; 19(12):2718-2725.

Gad HA, El-Ahmady SH, Abou-Shoer MI, Al-Azizi MM. Application of Chemometrics in Authentication of Herbal Medicines: A Review. Phytochem Anal, 2013; 24:1-24.

Gemperline P. 2006. Practical Guide to Chemometrics. Boca Raton: CRC/Taylor \& Francis.

Gendrin C, Roggo Y, Collet C. Pharmaceutical applications of vibrational chemical imaging and chemometrics: A review. J Pharm Biomed Anal, 2008; 48:533-553.

Griffiths P, Chalmers JM. 2002. Handbook of vibrational spectroscopy. New York: John Wiley and Sons.

Hannah RW. 2002. Standard sampling techniques for infrared spectroscopy. In: Chalmers JM, Griffiths PR, Eds. Handbook of vibrational spectroscopy, vol. 2. London: John Wiley \& Sons 933-952.

Hanrahan G, Gomez FA. 2010. Chemometric Methods in Capillary Electrophoresis. Hoboken, NJ: J. Wiley \& Sons, Inc.

Hashin DM, Che Man YB, Norakasha R, Shuhaimi M, Salmah Y, Syahariza ZA. Potential use of Fourier transform infrared spectroscopy for differentiation of bovine and porcine gelatins. Food Chem, 2010; 118:856-860

Hemmateenejad B. Chemometrics in Iran. Chem Intel Lab Sys, 2006; 81:202-208.

Kalantri PP, Somani RR, Makhija T. Raman spectroscopy: a potential technique in analysis of pharmaceuticals. Der Chem Sin, 2010; $1: 1-12$.

Khattak JZK, Mir A, Anwar Z, Wahedi HM, Abbas G, Khattak HZK, Ismatullah H. Concept of halal food and biotechnology. Adv J Food Sci Technol, 2011; 3(5):385-389.

Kokot S, Grigg M, Panayiotou H, Phuong TD. Data interpretation by some common chemometrics methods (tutorial review). Electroanalysis, 1998; 10(16):1081-1088.

Lubis HN, Mohd-Naim NF, Alizul NN, Ahmed MU. From market to food plate: Current trusted technology and innovations in halal food analysis. Trends Food Sci Technol, 2016; 58:55-68.

Lukitaningsih E, Saadah M, Purwanto, Rohman A. Quantitative Analysis of Lard in Lotion Cosmetics Formulation Using FTIR
Spectroscopy And Partial Least Square Calibration. J Am Oil Chem Soc, 2012; 89:1537-1543.

Luypaert J, Massart DL, Vander Heyden Y. Review Nearinfrared spectroscopy applications in pharmaceutical analysis. Talanta, 2007; 72:865-883

Miller JN, Miller JC. 2010. Statistics and chemometrics for Analytical Chemistry, $5^{\text {th }}$ ed. Harlow, England: Prentice Hall.

Nakyinsige K, Che Man YB, Sazili AQ. Review Halal authenticity issues in meat and meat products. Meat Sci, 2012; 91:207-214.

Norgaard L. A multivariate chemometric approach to fluorescence spectroscopy. Talanta, 1995; 42:1305-1324.

Pavia DL, Lampman GM, Kriz-jr GS. 2009. Introdoction to Specroscopy: A Guide for Students of Organic Chemistry. Philadelpia, USA: W.B. Saunders Company.

Ragno G, Ioele G, Risoli A. Multivariate calibration techniques applied to the spec-trophotometric analysis of one-to-four component systems. Anal Chimica Acta, 2004; 512:173-180.

Regenstein JM, Chaudry MM, Regenstein CE. The kosher and halal food laws. Comprehen. Rev Food Sci Food Saf, 2003; 2(3):111-127.

Reich G. Near-infrared spectroscopy and imaging: Basic principles and pharmaceutical applications. Adv Drug Deliv Rev, 2005; 57:1109-1143.

Rinnan A. Pre-processing in vibrational spectroscopy-when, why and how. Anal Methods, 2014; 6:7124-7129.

Rohman A. Application of FTIR spectroscopy for quality control in pharmaceutical products: a review. Indonesian J Pharm, 2012; 23(1):1-8.

Rohman A, Nugroho A, Lukitaningsih E, Sudjadi. Application of Vibrational Spectroscopy in Combination with Chemometrics Techniques for Authentication of Herbal Medicine. App Spectros Rev, 2014; 49:603613. Doi: 10.1080/05704928.2014.882347.

Rohman A, Arsyanti L, Erwanto Y, Pranoto Y. The use of vibrational spectroscopy and chemometrics in the analysis of pig derivatives for halal authentication. Int Food Res J, 2016; 23(5):1839-1848.

Rohman A. The use of infrared spectroscopy in combination with chemometrics for quality control and authentication of edible fats and oils: A review. App Spectros Rev, 2017. Doi: 10.1080/05704928.2016.1266493.

Rohman A, Che Man YB. Analysis of Lard in Cream Cosmetics Formulations using FT-IR Spectroscopy and Chemometrics. Middle-East J Sci Res, 2011; 7(5):726-732

Rohman A, Che Man YB. Analysis of pig derivatives for halal authentication studies. Food Rev Int, 2012; 28(1):97-112.

Rohman A, Kuwat T, Retno S, Sismindari, Yuny E, Tridjoko W. Fourier Transform Infrared Spectroscopy applied for rapid analysis of lard in palm oil. Int Food Res J, 2012; 19:1161-1165.

Sádecká J, Tóthová J. Fluorescence spectroscopy and chemometrics in the food classification a review. Czech J Food Sci, 2007; $25: 159-173$

Skoog DA, Holler FJ, Crouch SR. 2007. Principles of Instrumental Analysis, 6th Ed. Belmont, USA: Thomson Higher Education.

Wang P, Sun J, Zhang T, Liu W. Vibrational spectroscopic approaches for the quality evaluation and authentication of virgin olive oil. App Spectros Rev, 2016; 51:763-790.

Wartewig S, Neubert RHH. Pharmaceutical applications of MidIR and Raman spectroscopy. Adv Drug Deliv Rev, 2005; 57:1144-1170.

Waskito D, Lukitaningsih E, Sudjadi, Rohman A. Analysis of Lard in Lipstick Using FTIR Spectroscopy and chemometrics: A Comparison of Three Extraction Methods. J Oleo Sci, 2016; 65(10):815824

How to cite this article:

Abdul Rohman, Salamah N. The employment of spectroscopic techniques coupled with chemometrics for authentication analysis of halal pharmaceuticals. J App Pharm Sci, 2018; 8(10): 063-068 